\title{
Value of selective screening for congenital adrenal hyperplasia in Hungary
}

\author{
J SOLYOM* AND I A HUGHES† \\ *Second Department of Paediatrics, Semmelweis University Medical School, Budapest, and †Department of \\ Child Health, University of Wales College of Medicine, Cardiff
}

SUMMARY Measurement of the 17-hydroxyprogesterone concentration in blood spots was used to identify cases of congenital adrenal hyperplasia among patients with inappropriate virilisation, or salt wasting, or both. Between 1978 and 198661 were identified among 707 patients (278 neonates, 204 infants, and 225 children).

The incidence of classic congenital adrenal hyperplasia was calculated for a seven year prospective trial period using the blood spot 17-hydroxyprogesterone method in selective screening. There were 38 salt losers and 14 simple virilisers in 968303 live births, an incidence of congenital adrenal hyperplasia of 1:18 000 in the Hungarian population. Selective screening led to earlier diagnosis of congenital adrenal hyperplasia and a pronounced decrease in mortality. A central laboratory to measure the blood spot 17-hydroxyprogesterone concentrations is valuable for the investigation of patients at risk for congenital adrenal hyperplasia in countries where blood steroid assays are not readily available.

Congenital adrenal hyperplasia is the result of 21-hydroxylase enzyme deficiency in more than $90 \%$ of cases. ${ }^{1}$ The plasma 17-hydroxyprogesterone concentration is usually raised and its measurement is a rapid and reliable test in patients suspected of having congenital adrenal hyperplasia. ${ }^{2-4}$ Though the assay is routinely available in steroid laboratories in western countries, in other countries such as Hungary the techniques for the provision of rapid results are seldom available.

A method for the measurement of 17hydroxyprogesterone in blood spotted on to filter paper was first reported in $1977 . .^{5}$ The method was originally intended for the screening of neonates for congenital adrenal hyperplasia, but a modified blood spot method was developed for the rapid diagnosis of patients suspected of having congenital adrenal hyperplasia throughout Hungary. ${ }^{6}$ Preliminary experience with the use of a blood spot 17hydroxyprogesterone assay to detect infants at risk of congenital adrenal hyperplasia has been previously reported. ${ }^{7}$ This paper reports on the use of this test to screen more than 700 patients at risk during an eight year period. The results also provide information on the incidence of congenital adrenal hyperplasia in Hungary.

\section{Patients and methods}

Between October 1978 and December 1986, 707 patients considered to be at risk of developing congenital adrenal hyperplasia were studied. The indications for investigation were inappropriate virilisation at any age, or salt wasting during the first month of life. The number of patients investigated in each age group was as follows: $1-3$ days, $67 ; 4-7$ days, 73 ; $8-30$ days, $138 ; 2-3$ months, $145 ; 4-12$ months, $59 ; 2-8$ years, $145 ; 9-18$ years, 80 .

Capillary blood was spotted on to the filter paper cards that are routinely used for the screening of neonates for phenylketonuria and congenital hypothyroidism. Samples were collected during the morning from patients older than 2 months of age because of the decline in 17-hydroxyprogesterone concentrations that occurs later in the day. ${ }^{8}$ Cards were posted to a central laboratory; the stability of steroids in dried blood spots kept at room temperature for 150 days has been reported previously. ${ }^{9}$ Serial capillary blood samples were also collected from some patients with congenital adrenal hyperplasia before treatment was started.

The assay for the measurement of blood spot 17-hydroxyprogesterone concentration has been 
published in detail. ${ }^{6}{ }^{10}$ The sensitivity of the method was $10 \mathrm{pg} /$ disc, equivalent to $10 \mathrm{nmol} / \mathrm{l}$ of serum. Results were available within 24 hours of receiving the sample in the laboratory.

\section{Results}

During the eight year study period 61 patients with 21-hydroxylase deficiency were identified using the blood spot 17-hydroxyprogesterone method among 707 patients with suspected congenital adrenal hyperplasia. The distribution of blood spot 17hydroxyprogesterone values in each age group is shown in figs 1,2 , and 3 .

Twenty six infants with salt losing congenital adrenal hyperplasia were identified among 278 patients investigated at age 1-30 days because of ambiguous genitalia, or salt wasting, or both (fig 1). The values of 17-hydroxyprogesterone at age 4-7 days were higher in ill babies born at full term and healthy premature infants compared with healthy babies born at full term (range: $10-140 \mathrm{nmol} / \mathrm{l}$ ). Using a cut off value of 17-hydroxyprogesterone of
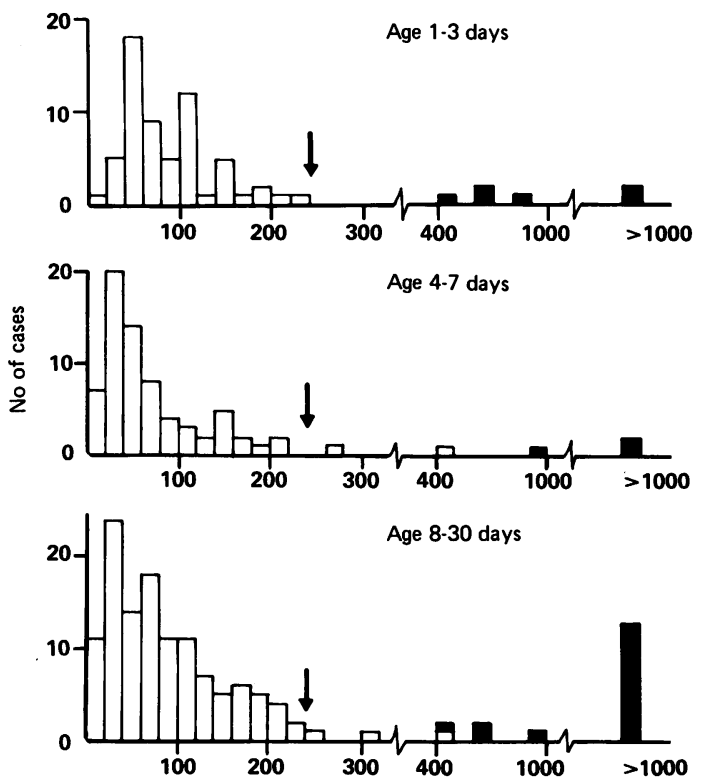

Blood spot 17-hydroxyprogesterone (nmol/l)

Fig 1 Frequency distribution of blood spot

17-hydroxyprogesterone values in infants at risk of congenital adrenal hyperplasia during the first month of life. Closed bars represent infants with congenital adrenal hyperplasia; there were six of 67 at age 1-3 days, three of 73 at age 4-7 days, and 17 of 138 at age 8-30 days. The arrow denotes the selected cut off value for

17-hydroxyprogesterone.

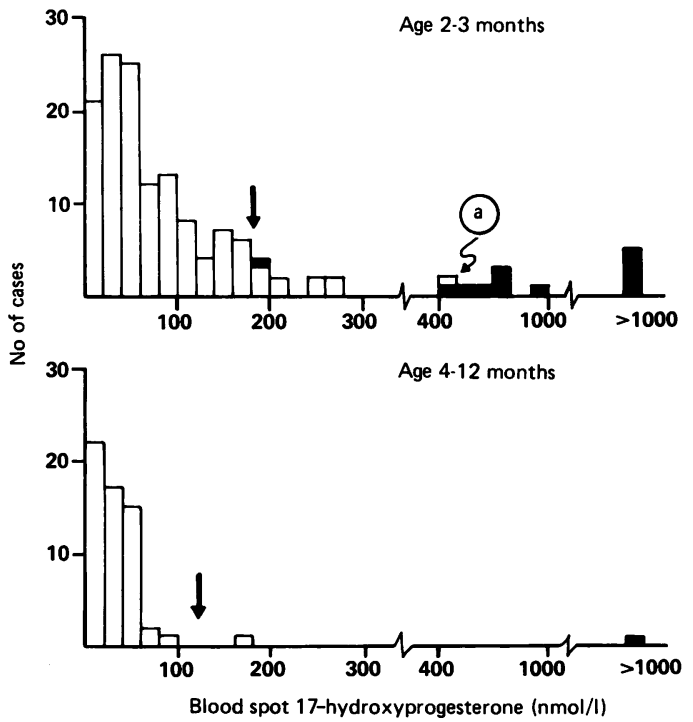

Fig 2 Frequency distribution of blood spot 17-hydroxyprogesterone values in children aged 2-12 months at risk of congenital adrenal hyperplasia; (a) indicates an infant with 11 $\beta$-hydroxylase deficiency. Closed bars represent infants with congenital adrenal hyperplasia; there were 13 of 145 at age 2-3 months and one of 59 at age 4-12 months. The arrow denotes the selected cut off value for 17-hydroxyprogesterone.

$240 \mathrm{nmol} / \mathrm{l}$ for the diagnosis of congenital adrenal hyperplasia there were five false positive and no false negative cases. Three of these infants were boys with hyponatraemia secondary to renal tract malformations and infection. The other two infants were premature girls in whom the clitoris was prominent.

Fig 4 shows the results of serial blood spot 17-hydroxyprogesterone meaurements in infants with congenital adrenal hyperplasia compared with those from healthy babies born at full term, and very low birthweight premature infants without congenital adrenal hyperplasia. There was some overlap in 17-hydroxyprogesterone values on the first day of life, when three very low birthweight premature infants had concentrations above $500 \mathrm{nmol} / \mathrm{l}$. Their raised values declined rapidly over a few days, however, whereas blood spot 17-hydroxyprogesterone concentrations in infants with congenital adrenal hyperplasia showed pronounced increases.

Fourteen patients with 21-hydroxylase deficiency (two of whom were not salt losers) were identified from 204 infants aged 2-12 months who were investigated for problems such as failure to thrive, dehydration, and enlarged clitoris with labial fusion. 

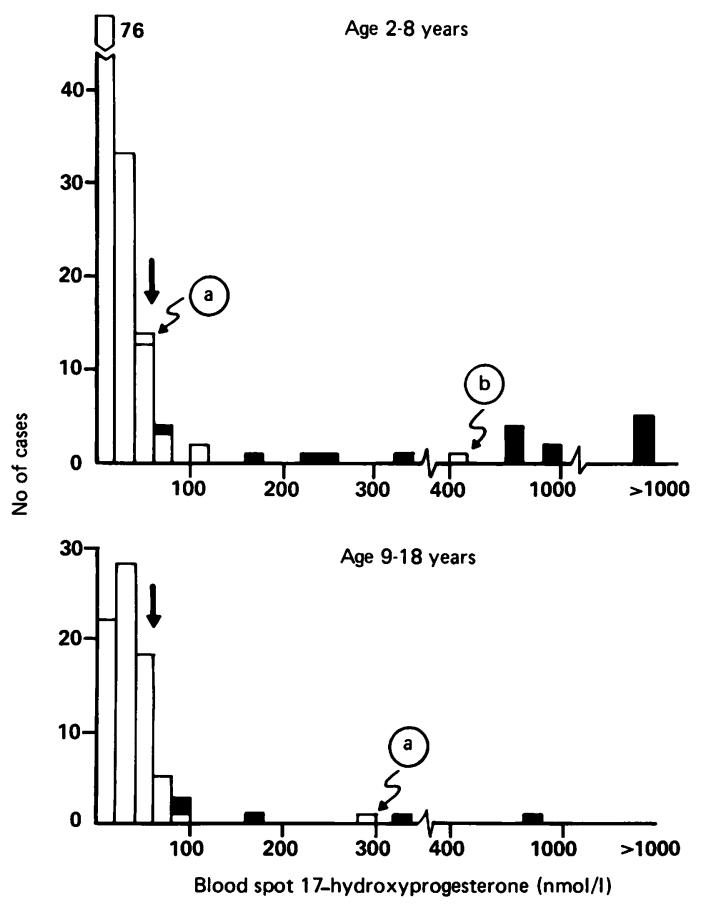

Fig 3 Frequency distribution of blood spot 17-hydroxyprogesterone values in children at risk of congenital adrenal hyperplasia at 2-18 years; $(a)$ and (b) indicate patients with $11 \beta$-hydroxylase deficiency and virilising adrenal carcinoma, respectively. Closed bars represent infants with congenital adrenal hyperplasia; there were 16 of 145 at age 2-8 years and five of 80 at age 9-18 years. The arrow denotes selected cut off value for 17-hydroxyprogesterone.

(fig 2). Blood spot 17-hydroxyprogesterone cut off limits of 180 and $120 \mathrm{nmol} / \mathrm{l}$ at 2-3 and 4-12 months, respectively, identified all the patients with congenital adrenal hyperplasia. Of 11 false positive results, one infant had $11 \beta$-hydroxylase deficiency; the other 10 patients had normal blood spot 17hydroxyprogesterone concentrations when the test was repeated. Among 225 patients aged $2-18$ years who had either premature pubarche or hirsutism there were 21 cases of congenital adrenal hyperplasia (including 14 who were not salt losers, and seven who had the late onset form) who were identified using a cut off value of 17-hydroxyprogesterone of $60 \mathrm{nmol} / \mathrm{l}$. Different cut off points for 17-hydroxyprogesterone in each age group were needed to avoid false negative results and ensure as low a number as possible of false positive results. Among the false positive results were a patient with an adrenal carcinoma and two cases of $11 \beta$ - hydroxylase deficiency. The median time from birth to the diagnosis of congenital adrenal hyperplasia in 38 salt losing cases was 17 days (range four to 38 ). This compares with 35 days (range 7-120) in a comparable number of salt losing cases analysed in a retrospective study.

Table 1 shows the number of patients with congenital adrenal hyperplasia born in Hungary during a 20 year period from 1966 to 1985 . The cases were found by examination of hospital medical records and later (from 1979 to 1985) prospectively

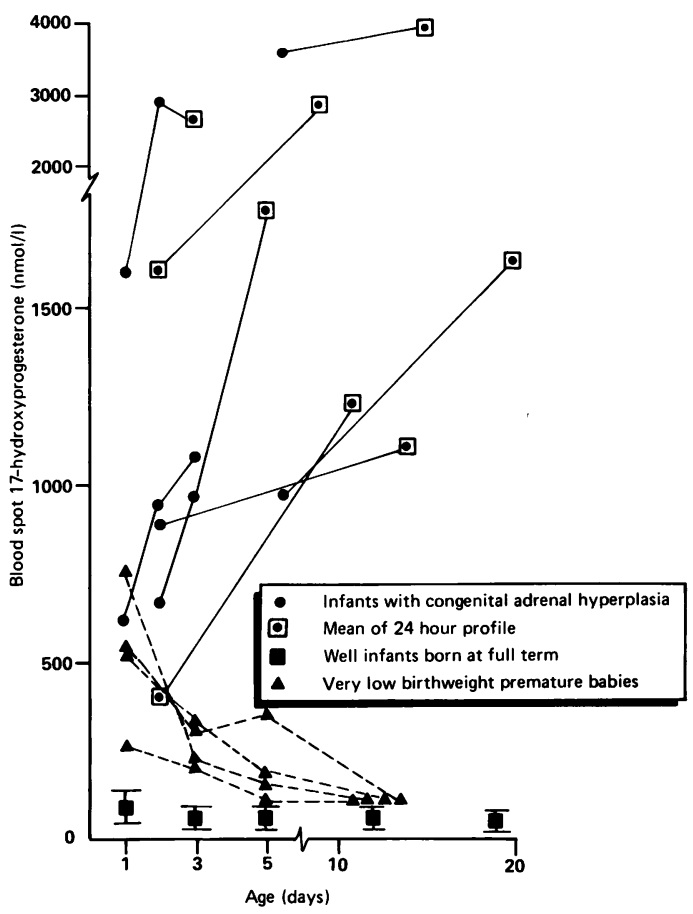

Fig 4 Serial blood spot 17-hydroxyprogesterone values in eight infants with congenital adrenal hyperplasia and in 12 infants born at full term and four very low birthweight infants without congenital adrenal hyperplasia during the first 20 days of life. Figures are given as mean (SD).

Table 1 Number of patients with congenital adrenal hyperplasia born in Hungary, 1966-1985

\begin{tabular}{llcc}
\hline Enzyme defect & Girls & Boys & $\begin{array}{l}\text { Total } \\
\text { No }\end{array}$ \\
\hline 21-hydroxylase: & & & \\
Salt losers & 37 & 42 & 79 \\
Simple virilisers & 25 & 18 & 43 \\
Late onset & 11 & 2 & 13 \\
11ß-hydroxylase & 1 & 3 & 4 \\
\hline
\end{tabular}


Table 2 Incidence of classic congenital adrenal hyperplasia in Hungary

\begin{tabular}{|c|c|c|c|c|c|c|}
\hline \multirow{2}{*}{$\begin{array}{l}\text { Method of } \\
\text { analysis }\end{array}$} & \multirow{2}{*}{$\begin{array}{l}\text { Period of } \\
\text { survey }\end{array}$} & \multirow{2}{*}{$\begin{array}{l}\text { No of } \\
\text { live births }\end{array}$} & \multicolumn{3}{|c|}{ No of cases } & \multirow{2}{*}{$\begin{array}{l}\text { Estimated } \\
\text { incidence }\end{array}$} \\
\hline & & & $\begin{array}{l}\text { Salt } \\
\text { losers }\end{array}$ & $\begin{array}{l}\text { Simple } \\
\text { virilisers }\end{array}$ & $\begin{array}{l}\text { Total } \\
\text { No }\end{array}$ & \\
\hline Retrospective case survey & $1966-1978$ & 2119727 & 41 & 29 & 70 & $1: 30282$ \\
\hline Prospective selective screening & $1979-1985$ & 968303 & 38 & 14 & 52 & $1: 18621$ \\
\hline
\end{tabular}

by measurement of blood spot 17-hydroxyprogesterone values in patients at risk. There was an equal incidence in boys and girls and two thirds were salt losers. The incidence of congenital adrenal hyperplasia among live births during the 20 year period was $1: 25312$. The incidence for the last seven years of this period is shown in table 2 . The estimated incidence was higher during the period of selective screening compared with that obtained by retrospective analysis. The presumed incidence of congenital adrenal hyperplasia in Hungary between 1979 and 1985 was $1: 18600$ with $95 \%$ confidence limits of 1:14 642 to $1: 25572$. One country area had 11 salt losers during this period (1966-1985), an incidence five times greater than that in the whole country.

\section{Discussion}

This study shows the value of 17-hydroxyprogesterone measurements in identifying congenital adrenal hyperplasia among patients within a wide age range with inappropriate virilisation or salt wasting. The restriction of screening to a population at risk rather than mass screening at birth is an option recently introduced in Italy. ${ }^{11}$ The present study reports the largest series of infants with congenital adrenal hyperplasia identified during the neonatal period by the blood spot 17hydroxyprogesterone method. The results confirm previous reports of the accuracy of this method for screening for congenital adrenal hyperplasia in the newborn. ${ }^{12-14}$ We found a higher false positive rate because those patients at risk were more likely to have, for example, salt wasting than the population identified by mass screening. Acute illness in infants, particularly if they are premature, can lead to the secretion of large amounts of adrenocortical hormones. ${ }^{15-16}$ Steroid concentrations normally fall rapidly once the stressful period is over. Diagnosis when there are only moderate rises of 17hydroxyprogesterone concentrations above the cut off value for age, as in $11 \beta$-hydroxylase deficiency, requires detailed plasma steroid analysis and specific gas chromatographic determination of urinary steroid excretion.
In a recent workshop on screening for congenital adrenal hyperplasia ${ }^{17}$ it was emphasised that the increased awareness of cases at risk (listed in table 3 ) and the ready availability of a rapid 17hydroxyprogesterone assay ${ }^{4}$ should result in a low incidence of undetected classical cases of congenital adrenal hyperplasia. A retrospective survey of 117 patients with congenital adrenal hyperplasia in Birmingham during a 30 year period showed an improvement in early diagnosis in children born after $1970 .{ }^{18}$ The change was attributed to the factors previously mentioned, and the authors concluded that a neonatal screening programme for congenital adrenal hyperplasia in the UK was not necessary. The need is clearly different in Hungary where routine 17-hydroxyprogesterone measurements are not yet available. A central laboratory that is able to provide rapid results of 17hydroxyprogesterone concentrations in blood spots collected from a restricted group at risk is a satisfactory alternative. The procedure has led to earlier diagnosis and treatment, and a reduction in mortality from $27 \%$ in $1966-78$ to $8 \%$ in $1979-85$.

Data are now available from a national register of all cases of congenital adrenal hyperplasia in Hungary. The ratio of salt losers to simple virilisers in classic congenital adrenal hyperplasia and the incidence of 1:18 000 are similar to those in other European countries. ${ }^{19-21}$ One region of Hungary seems to have an increased incidence of salt losing congenital adrenal hyperplasia, although it is still lower than those reported from Alaska ${ }^{22}$ and La Reunion. $^{14}$ Selective screening for congenital adrenal hyperplasia is a practical option that can yield valuable clinical information and more accurate estimate of incidence.

Table 3 Cases of congenital adrenal hyperplasia readily identifiable at birth

All affected girls (theoretically)

Salt losers

Apparent cryptorchid boys with hypospadias

Those with a previous family history of congenital adrenal hyperplasia

Those with a positive prenatal diagnosis 


\section{References}

1 Hughes IA. Congenital and acquired disorders of the adrenal cortex. Clin Endocrinol Metab 1982;11:89-125.

2 Youssefnejadian E, David R. Early diagnosis of congenital adrenal hyperplasia by measurement of 17-hydroxyprogesterone. Clin Endocrinol 1975;4:451-4.

3 Hughes IA, Fahmy DR, Griffiths K. Plasma 170H-progesterone concentrations in newborn infants. Arch Dis Child 1979;54: 347-9.

4 Dyas J, Read GF, Guha-Maulik T, Hughes IA, Fahmy DR. A rapid assay for $170 \mathrm{H}$-progesterone in plasma, saliva and amniotic fluid using a magnetisable solid-phase antiserum. Ann Clin Biochem 1984;21:421-4.

5 Pang S, Hotchkiss J, Drash AL, Levine LS, New MI. Microfilter paper method for 17-hydroxyprogesterone radioimmunoassay: its application for rapid screening for congenital adrenal hyperplasia. J Clin Endocrinol Metab 1977;45:1003-8.

6 Sólyom J, Hammond GL, Vihko R. A method for identification and follow-up of patients with a steroid 21-hydroxylase deficiency. Clin Chim Acta 1979;92:117-24.

7 Sólyom J, Hervei S, Marossy P, Sólyom E, Babosa M, Szombathy G. "Dot-17alpha-hydroxyprogesterone" radioimmunoassay for identification of congenital adrenal hyperplasia in young infants. Acta Paediatr Scand 1981;70:913-7.

${ }^{8}$ Sólyom J. Diurnal variation in blood 17-hydroxyprogesterone concentrations in untreated congenital adrenal hyperplasia. Arch Dis Child 1984;59:743-7.

9 Sólyom J. Analysis of steroid hormones in biological samples dried on filter paper. In: Görög S. Advances in steroid analysis. Budapest: Akadémiai Kiadó, 1982:201-5.

${ }^{10}$ Sólyom J. Comparative measurements of serum concentration and blood spot level of 17-hydroxyprogesterone in congenital adrenal hyperplasia. In: Görög S. Advances in steroid analysis. Budapest: Akadémiai Kiadó, 1985:207-11.

11 Cacciari E, Balsamo A, Cassio A, et al. Neonatal screening programme for congenital adrenal hyperplasia in a homogeneous Caucasian population. J Inherited Metab Dis 1986;9(suppl 1):142-6.

12 Shimozawa K, Saisho S, Saito N, et al. A neonatal mass- screening for congenital adrenal hyperplasia in Japan. Acta Endocrinol 1984;107:513-8.

13 Wallace AM, Beastall GH, Cook B, et al. Neonatal screening for congenital adrenal hyperplasia: a programme based on a novel direct radioimmunoassay for 17-hydroxyprogesterone in blood spots. $J$ Endocrinol 1986;108:299-308.

14 Dhondt JL, Dorche C, Farriaux JP, Courte C. Neonatal screening for congenital adrenal hyperplasia: a pilot study in France. J Inherited Metab Dis 1986;9(suppl 1):147-51.

15 Murphy JF, Joyce B, Dyas J, Hughes IA. Plasma 17hydroxyprogesterone concentrations in ill newborn infants. Arch Dis Child 1983;58:532-4.

${ }^{16}$ Hughes D, Murphy JF, Dyas J, Robinson JA, Fahmy DR, Hughes IA. Blood spot glucocorticoid concentrations in ill preterm infants. Arch Dis Child 1987;62:1014-8.

17 Hughes IA. Clinical aspects of congenital adrenal hyperplasia: early diagnosis and prognosis. $J$ Inherited Metab Dis 1986;9(suppl 1):115-23.

18 Virdi NK, Rayner PHW, Rudd BT, Green A. Should we screen for congenital adrenal hyperplasia? A review of 117 cases. Arch Dis Child 1987;62:659-62.

19 Werder EA, Siebenmann RE, Knorr-Murset G, et al. The incidence of congenital adrenal hyperplasia in Switzerland: a survey of patients born in 1960-1974. Helv Paediatr Acta 1980;35:5-11.

${ }^{20}$ Murtaza L, Sibert JR, Hughes IA, Balfour IC. Congenital adrenal hyperplasia-a clinical and genetic survey. Arch Dis Child 1980;55:622-5.

${ }^{21}$ Bois E, Mornet E, Chompret A, et al. L'hyperplasie congenitale des surrénales $(21-\mathrm{OH})$ en France. Génétique des populations. Arch Fr Pediatr 1985;42:175-9.

22 Pang S, Murphy W, Levine LS, et al. A pilot newborn screening for congenital adrenal hyperplasia in Alaska. J Clin Endocrinol Metab 1982;55:413-20.

Correspondence and requests for reprints to $\mathrm{Dr} \mathrm{J}$ Sólyom, 2nd Department of Paediatrics, Semmelweis University Medical School, H-1094 Budapest, Tuzoltó u.7, Hungary.

Accepted 18 July 1988 